\title{
Carbon balance assessment of a natural steppe of southern Siberia by multiple constraint approach
}

\author{
L. Belelli Marchesini ${ }^{1}$, D. Papale ${ }^{1}$, M. Reichstein ${ }^{1,2}$, N. Vuichard ${ }^{1}$, N. Tchebakova ${ }^{3}$, and R. Valentini ${ }^{1}$ \\ ${ }^{1}$ Department of Forest Resources and Environment, University of Tuscia, Via San Camillo de Lellis, 01100 Viterbo, Italy \\ ${ }^{2}$ Max Planck Institute for Biogeochemistry, Hans Knoll Str. 10, 07745, Jena, Germany \\ ${ }^{3}$ Sukachev Insitute of Forest, SB-RAS, Akademgorodok, Krasnoyarsk, 660036, Russia
}

Received: 30 October 2006 - Published in Biogeosciences Discuss.: 29 January 2007

Revised: 11 June 2007 - Accepted: 3 July 2007 - Published: 2 August 2007

\begin{abstract}
Steppe ecosystems represent an interesting case in which the assessment of carbon balance may be performed through a cross validation of the eddy covariance measurements against ecological inventory estimates of carbon exchanges (Ehman et al., 2002; Curtis et al., 2002).

Indeed, the widespread presence of ideal conditions for the applicability of the eddy covariance technique, as vast and homogeneous grass vegetation cover over flat terrains (Baldocchi, 2003), make steppes a suitable ground to ensure a constrain to flux estimates with independent methodological approaches.

We report about the analysis of the carbon cycle of a true steppe ecosystem in southern Siberia during the growing season of 2004 in the framework of the TCOS-Siberia project activities performed by continuous monitoring of $\mathrm{CO}_{2}$ fluxes at ecosystem scale by the eddy covariance method, fortnightly samplings of phytomass, and ingrowth cores extractions for NPP assessment, and weekly measurements of heterotrophic component of soil $\mathrm{CO}_{2}$ effluxes obtained by an experiment of root exclusion.

The carbon balance of the monitored natural steppe was, according to micrometeorological measurements, a sink of carbon of $151.7 \pm 36.9 \mathrm{~g} \mathrm{C} \mathrm{m}^{-2}$, cumulated during the growing season from May to September. This result was in agreement with the independent estimate through ecological inventory which yielded a sink of $150.1 \mathrm{~g} \mathrm{C} \mathrm{m}^{-2}$ although this method was characterized by a large uncertainty $( \pm 130 \%)$ considering the $95 \%$ confidence interval of the estimate. Uncertainties in belowground process estimates account for a large part of the error. Thus, in particular efforts to better quantify the dynamics of root biomass (growth and turnover) have to be undertaken in order to reduce the uncertainties in
\end{abstract}

Correspondence to: L. Belelli Marchesini

(belelli@unitus.it) the assessment of NPP. This assessment should be preferably based on the application of multiple methods, each one characterized by its own merits and flaws.

\section{Introduction}

Evidences from analysis of ${ }^{13} \mathrm{C} /{ }^{12} \mathrm{C}$ isotope ratios from a worldwide network of stations during 1992-1993 (Ciais et al., 1995), show that a large carbon sink (missing sink) in the global carbon budget may be located in the terrestrial regions of the Northern Hemisphere.

The challenge is now to identify the process that would cause the terrestrial biosphere to absorb quantities of carbon dioxide amounting to about one third the total emissions from fossil fuels. Some of this substantial new carbon storage may indeed comprise the aboveground biomass of northern temperate and boreal forests, but belowground allocation of considerable amounts of additional carbon to roots and soil organic matter (SOM) is likely to account for a significant fraction of the carbon sink (Hall and Scurlock, 1991) and can explain the sustained capacity of late successional ecosystems to act as net sink for atmospheric carbon dioxide (Schulze et al., 2000).

At present, most long-term carbon flux studies have focused on various temperate conifer and broadleaved (deciduous and evergreen) forests, tropical and boreal forests. Only a few long-term carbon flux studies have been conducted over grasslands (Meyers, 2001; Flanagan et al., 2002; Suyker and Verma, 2001; Gilmanov et al., 2003), even though grassland is the largest of the four major natural biomes (Sims and Risser, 2000) covering nearly one fifth of the world's land surface (Lieth, 1978).

Published by Copernicus Publications on behalf of the European Geosciences Union. 
In this respect, there is an increased awareness on the role of grasslands in the global carbon cycle, poorly recognized in the past (Hall and Scurlock, 1991; Hall et al., 1995), and more attention to their vulnerability to climate change and their likely impact on increase of greenhouse gases emissions should be given. Eurasian steppes cover 8 million $\mathrm{km}^{2}$, representing the largest area of grassland ecosystems globally, and they include the Central Asian steppes of Mongolia, Baikal, Altai, Hakasia and Tuva which sum up 223 million ha.

Most of previous work on productivity of central Asian steppes have been focussed on the assessment of Net Primary Productivity (NPP) (Titlianova et al., 2002), which by definition does not provide indications about the overall carbon sink or source strength of these ecosystems but only information on the inputs of carbon which, depending on its turnover as transient or long term soil carbon, constitute a route for $\mathrm{CO}_{2}$ sequestration (Trumbore et al., 1996; Bird et al., 1996; Batjes and Sombroek, 1997); thus, even modest changes in inputs to grassland carbon storage may result in significant and long lived sequestration.

Early estimates of grassland NPP were based solely on aboveground peak standing matter, and even the coordinated efforts to characterize grassland NPP by the International Biological Programme were based mainly on changes in aboveground biomass, with relatively few estimates of belowground production (Milner and Hughes, 1968; Singh and Joshi, 1975; Long et al., 1989).

Understanding belowground NPP is particularly important in grassland ecosystem since in most grasslands a large proportion of biomass is below ground (Coupland, 1992), making total NPP estimation particularly sensitive to estimates of belowground production.

Although advances have been made in accurately determining aboveground NPP (Gill et al., 2002; Paruelo et al., 1997; Raich et al., 1997; Sala and Austin, 2000), the amount of NPP allocated belowground remains among the most poorly understood attributes of ecosystems (Lauenroth, 2000). In the case of grasslands less than $10 \%$ of the studies consider direct measurements of the belowground biomass and losses, such as root exudation, were generally ignored, leading to a probable underestimation of their carbon fluxes (Long et al., 1989, 1992). Some of the findings point to a revisited role of grasslands in the carbon cycle and particularly of the boreal ones.

The use of micrometeorological methods, such as the eddy covariance (E.C.) technique has the advantage of providing Net Ecosystem Production (NEP) at ecosystem scale, including also the role of soil net uptake or release. However E.C., when applied over complex landscapes must include measurements of atmospheric storage, flux divergence and advection in the experimental set up (Baldocchi, 2003): these requirements are often too demanding for long term measurements and usually not implemented. For these reasons is very critical to provide additional cross checks and veri- fication between EC method and inventory type assessment. In this respect there are few studies which directly address a comparison of NEP derived by inventories of carbon pool changes and measured by eddy covariance.

Few studies show that EC measurements are converging with independent values produced by measuring changes in biomass and soil carbon (Curtis et al., 2002; Valentini et al., 2003), however validation of results of carbon budget retrieved by E.C. against measurements of changes of ecosystem carbon stocks is often problematic because the increments of biomass in root systems may be difficult to determine and the changes in soil carbon content may require long-term observations to be detected with statistical significance (Smith, 2004; Conen et al., 2003).

Steppe ecosystems represent a case in which the assessment of carbon balance may be performed with relative simplicity through a multiple constraint approach crossvalidating the eddy covariance measurements with independent NEP. Indeed, the structure of the vegetation of these ecosystems offer the possibility of collecting increments of the root system through periodic biomass measurements and to measure soil respiration excluding the contribution of root respiration in a less complicated way than for forest ecosystems. In addition conditions for negligible advective transport and homogeneous flux source areas (footprints) are more frequently met in this type of ecosystems, making steppes an ideal test-case for cross verification of eddy covariance and inventory techniques for annual carbon balance determination.

In this paper we report about the analysis of the carbon balance of a true steppe ecosystem in southern Siberia during the period 26 April-30 September 2004 in the framework of the TCOS-Siberia project activities. During this campaign we monitored continuously $\mathrm{CO}_{2}$ fluxes at ecosystem scale using the eddy covariance method and carried on samplings of phytomass fortnightly, in order to assess net primary productivity, and weekly measurements of soil respiration trying to partition the $\mathrm{CO}_{2}$ effluxes into autotrophic and heterotrophic components by an experiment of root exclusion.

Hence, our main objective was to assess the NEP as the difference between NPP and heterotrophic respiration to provide an independent constraint on meteorologically based estimates of the same variable. Importantly we quantify uncertainties in both approaches by (i) analyzing results of NPP assessments retrieved by different methodologies, (ii) by comparing night-time chamber based efflux measurements with ecosystem respiration retrieved by E.C. technique and further assessments of error sources in the eddy fluxes. 


\section{Methods}

\subsection{Site}

The research site is a natural graminoid small-tussock steppe in the Iyus-Shira region of the Republic of Hakasia and is located approximately $30 \mathrm{~km}$ north of the town of Shira $\left(54^{\circ} 72^{\prime} \mathrm{N} ; 90^{\circ} 00^{\prime} \mathrm{E}\right)$.

The climate at the site, according to the Koppen climate classification system (Thornthwaite, 1933), is semi-arid cool (BSk); climatic statistics determined on the base of archive data of Shira for the period 1942-1995, reveal a mean annual temperature of $0.4^{\circ} \mathrm{C}$, a seasonal temperature trend characterized by great continentality (difference between mean temperature of January and July is $35.0^{\circ} \mathrm{C}$ ) and annual precipitation of $304 \mathrm{~mm}$ out of which $245 \mathrm{~mm}$ distributed during summer season from May to September.

The soil is classified as a calcic chernozem (second level legend FAO-Unesco 1990) with fine surface texture and a proportion of clay ranging between 35 and 60\% (Stolbovoi, 2000). The soil organic horizon extends approximately as far as $30 \mathrm{~cm}$ depth and has a concentration of organic carbon (TOC) and nitrogen, of $2.22 \pm 0.15 \%$ and $0.24 \pm 0.02 \%$, respectively (mean \pm std; $n=60$ ) while soil bulk density is $1460 \mathrm{~kg} \mathrm{~m}^{-3}(\mathrm{n}=2)$.

This steppe was managed as a pasture until 2001 but because of the low grazing pressure, no major signs of disturbance over the vegetation composition and structure, compared to sites with no management history, were found.

Plant composition counts 102 species of 26 families, among which the most numerous belong to Asteraceae (21 species), Poaceae (16 species), Lamiaceae (6 species), Fabaceae (6 species) and Brassicaceae (6 species). Perennial living forms prevail $(76 \%)$ and dominant species are: Festuca valesiaca Gaudin, Koeleria cristata L., Stipa krylovi Roshev., Cleistogenes squarrosa Trin., and Poa botryoides Trin. ex Griseb (T. Bugaenko, personal communication).

\subsection{Biometric measurements}

Biomass samplings were carried out during the whole length of the growing season from the beginning of May to the end of September within the footprint area of the micrometeorological station.

Aboveground phytomass was sampled at intervals of two weeks within 20 randomly located square plots of $0.25 \mathrm{~m}^{2}$ each. The standing biomass was clipped at ground level and the litter was collected from the area of each plot; the matter was then sorted into live and dead biomass.

Belowground biomass was sampled once a month from 0 to $30 \mathrm{~cm}$ using a corer in the same plots as for aboveground biomass estimation. The sampling depth was determined by trial sampling in order to retrieve at least $90 \%$ of belowground matter. Roots and particulate organic matter were separated from the soil removing the larger roots by tweezers the rest being washed in water to retrieve the floating fragments of roots and dead organic matter sieving them over multiple layers of $1 \mathrm{~mm}$ sieves.

All the collected matter was dried in a stove at $70^{\circ} \mathrm{C}$ until completely dehydrated and weighed on an electronic scale; biomass was expressed as the weight of dry matter per unit area or $\left[\mathrm{t} \mathrm{d} . \mathrm{m} . \mathrm{ha}^{-1}\right]$.

The values of biomass were then converted to tons of carbon/ha, using 0.45 as conversion factor from biomass to carbon (IPCC, 2003).

\subsection{Net primary productivity}

Six algorithms are generally used for estimating NPP from biomass measurements in grassland vegetation: (1) peak live biomass, (2) peak standing crop (live plus standing dead matter), (3) maximum minus minimum live biomass, (4) sum of positive increments in live biomass, (5) sum of positive increments in live and dead plus litter, and (6) sum of changes in live and dead biomass with adjustment for decomposition (Scurlock et al., 2002).

Each of these methods can be applied only if specific assumptions (presence or absence of live or dead matter from previous years, negligibility of decomposition, simultaneity of biomass growth and death) are met. The algorithms used for the computation of NPP differ also in the number of inputs required to describe processes associated with biomass change over time (aboveground and belowground productivity, decomposition) and lead to different results in the assessment of NPP.

In this study we assessed net primary productivity using three methods:

\section{Method 1}

$$
\begin{aligned}
\mathrm{NPP}(\mathrm{AG}, \mathrm{BG}) & =\Sigma(\Delta((\mathrm{AG}, \mathrm{BG}) \text { bmass }+(\mathrm{AG}, \mathrm{BG}) \text { Totdead })) \\
& =\Sigma(\Delta(\text { AGTotmat }+ \text { BGTotmat })) ; \Delta>0 \quad(1)
\end{aligned}
$$

Singh and Joshi (1975)

Method 2

$$
\begin{aligned}
\mathrm{NPP}(\mathrm{AG}, \mathrm{BG})= & \Sigma(\Delta(\mathrm{AG}, \mathrm{BG}) \text { bmass }+\Delta(\mathrm{AG}, \mathrm{BG}) \text { Totdead } \\
& \left.+\left(r_{(a g, b g)} \cdot(\mathrm{AG}, \mathrm{BG}) \text { Totdead }\right)\right) \\
= & \Sigma\left(\Delta \mathrm{AGTotmat}+\Delta \mathrm{BGTotmat}+\left(r_{(a g, b g)}\right.\right. \\
& \cdot(\mathrm{AG}, \mathrm{BG}) \text { Totdead }))
\end{aligned}
$$

Long et al. (1989); Weigert and Evans (1964).

\section{Method 3}

$\mathrm{NPP}(\mathrm{AG})=\Sigma(\Delta((\mathrm{AG})$ bmass $+(\mathrm{AG})$ Totdead $)) ; \Delta>0$

$\mathrm{NPP}(\mathrm{BG})=\Delta \mathrm{BGTotmat}($ ingrowth_cores)

where AGbmass $=$ aboveground live matter; AGTotdead $=$ aboveground total dead matter; BGbmass = belowground live biomass; BGTotdead = belowground total dead matter; 
$r_{a g}=$ aboveground relative rate of decomposition; $r_{b g}=$ belowground relative rate of decomposition; AGTotmat = aboveground total matter; BGTotmat $=$ belowground total matter; BGTotmat(ingrowth_cores) = belowground total matter in in growth cores.

Method (1) assumes that growth, death and decomposition do not occur simultaneously and it does not account for material lost by death during periods of biomass increase.

Method (2) assumes a) that measured changes in parameters are statistically significant over each sample interval, although in practice this may be very hard to achieve as an impractically large number of samples would be required to detect real but modest changes over each sampling period (Scurlock et al., 2002), b) that decomposition rate is independent of the composition of dead matter, and c) that exports of biomass are negligible (i.e. grazing, root exudation, etc.); yet it is the only method which incorporates all components required for an accurate estimate of NPP, including adjustment for decomposition. To retrieve the relative rates of decomposition, the decrease of decomposing dead matter over time was assumed to follow a negative exponential trend (Olson, 1963; Koukura et al., 2003), described by the equation:

$X=X_{o} e^{-k t}$

where $X=$ undecomposed matter quantity; $X_{o}=$ initial quantity at time $t[\mathrm{~d}] ; k=$ rate constant $\left[\mathrm{d}^{-1}\right]$

The fraction of dead matter which decomposes in time $t$ as percentage of the initial quantity, corresponds to the relative rate of decomposition $(r)$ and can be expressed as follows:

$r=\frac{\left(X_{o}-X\right)}{X}=\left(1-e^{-k t}\right)$

inverting the equation the constant $\mathrm{k}$ may be retrieved

$k=-\frac{\ln (1-r)}{t}$

Decomposition rates may be determined experimentally using litter bags containing dead aboveground matter, placed at the ground surface, or dead belowground matter buried in the soil; at the end of the sample interval the bags are recovered and the loss of material is quantified. In this work we referred to results of observations of decomposition rates made in steppes of central Asia after Titlianova (1977), in order to retrieve specific constant rates $(k)$ : these were $1.18 \times 10^{-3}$ and $1.89 \times 10^{-3} \mathrm{~d}^{-1}$ for aboveground and belowground dead matter, respectively. The application of the adjustment for decomposition in method (2) requires the knowledge of the amount of dead matter which undergoes this process: as we did not separate belowground biomass into live and dead we assume the ratio between belowground live and total biomass to be 0.4 , an average value for natural steppe ecosystems of Hakasia (Titlianova, 1977).

Method (3) assess aboveground NPP as in method (1), while belowground NPP is given by root biomass increments measured by the method of ingrowth cores (Jordan and Escalante, 1980; Persson, 1983; Cuevas and Medina, 1988; Neill, 1992; Fisk et al., 1998; Johnson and Matchett, 2001). This technique although is quite feasible and lets to avoid the necessary assumptions for the assessment of NPP by sequential biomass, on the other hand suffers from two major limitations: 1) it enhances root proliferation due to disturbance and altered nutrient availability in disturbed root-free soils and 2) it underestimates root growth because of disappearance of roots over the measurement period (Fahey and Hughes, 1994).

\section{$2.4 \mathrm{CO}_{2}$ flux measurements (Eddy Covariance)}

Continuous measurements of wind speed along three orthogonal components $(u, v, w)$, sonic temperature $(T s), \mathrm{CO}_{2}$ concentration $\left(\rho_{c}\right)$ and water vapour $\left(\rho_{v}\right)$ density were carried out with an array of instruments including a 3-D sonic anemometer (1012R3, Gill Instruments, UK) and a fast response open path infra-red gas analyzer (LI7500, LiCor Inc., USA) mounted on the top of a $4.5 \mathrm{~m}$ tower. The raw data from each $30 \mathrm{~min}$ period were recorded at a rate of $20 \mathrm{~Hz}$ and stored into separate files on a laptop computer. Calibration of the IRGA was done at regular intervals of 1 month for $\mathrm{CO}_{2}$ using a gas mixture referenced to NOAA/CMDL standard. Zeroes for both $\mathrm{CO}_{2}$ and water vapour channels were calibrated with pure $\mathrm{N}_{2}$ gas. The eddy flux system used approximately $4 \mathrm{~A}$ at $12 \mathrm{~V}$ and was powered by six $12 \mathrm{VDC}$ batteries which were charged daily for $2 \mathrm{~h}$ by a generator placed $50 \mathrm{~m}$ $\mathrm{E}$ from the tower, downstream of dominant winds. In case exhaust gases were blown towards the tower, data collected during the operation of recharge were rejected.

Standard meteorological and soil parameters were measured continuously: photosynthetic photon flux density (PPFD), diffuse PPFD, and net radiation ( $\mathrm{Rn})$ were measured at the height of $3 \mathrm{~m}$ by quantum sensors (SKP215, Skye, UK) and a net radiometer (Q7, REBS, USA), respectively. Air temperature (Tair) and relative humidity $(\mathrm{RH})$ were measured at the height of $2.5 \mathrm{~m}$ with a shielded sensor (HP102, TecnoEl, Italy). Precipitation was measured with a tipping bucket rain gauge (ARG100, TecnoEl, Italy), atmospheric pressure was measured by a barometer (TP800, TecnoEl, Italy). Soil temperature (Tsoil) was measured at the depths of 0.05 and $0.1 \mathrm{~m}$ by thermistors (107, Campbell Scientific, UK) and soil moisture (SM) was measured with a time-domain reflectometer (CS615, Campbell Scientific, UK) as an averaged value up to the depth of $0.3 \mathrm{~m}$. Soil heat flux $(\mathrm{G})$ was measured by a heat flux plate (HFT1, Rebs, USA) buried at the depth of $0.05 \mathrm{~m}$.

All channels from sensors were scanned every $30 \mathrm{~s}$ and data were stored as 30 min mean by a data-logger (CR10X, Campbell Scientific, UK).

$\mathrm{CO}_{2}$ flux $(F c)$, after 3-D rotation of coordinates according to Aubinet et al. (2000), was calculated as the product of the mean covariance of vertical wind speed fluctuations $\left(w^{\prime}\right)$ 
and the $\mathrm{CO}_{2}$ density fluctuations $\left(\rho^{\prime}{ }_{c}\right)$ added by terms to account for air density fluctuations over mean vertical velocity according to the equation (Webb et al., 1980):

$F c=\overline{w^{\prime} \rho_{c}^{\prime}}+\frac{m_{a}}{m_{v}} \frac{\overline{\rho_{c}}}{\overline{\rho_{a}}} \overline{w^{\prime} \rho_{v}^{\prime}}+\left(1+\frac{\overline{\rho_{v}} m_{a}}{\overline{\rho_{a}} m_{v}}\right) \frac{\overline{\rho_{c}}}{\bar{T}} \overline{w^{\prime} T^{\prime}}$

where $\rho_{a}$ is dry air density, $m_{a}$ and $m_{v}$ are molecular weight of air and water vapour, respectively.

Loss of the high frequency component of Fc resulting from factors such as spatial separation of instruments for measurements of wind speed and $\mathrm{CO}_{2} / \mathrm{H}_{2} \mathrm{O}$ densities, limitation in the response time of the sensors, averaging associated with the sample volume of the gas analyzer path and between the transducers of the sonic anemometer (Aubinet et al., 2000; Moncrieff et al., 1996) was accounted for by comparing normalized co-spectra of vertical wind velocity and temperature (which represent the entire turbulent sensible heat flux density without losses) to co-spectra of vertical wind velocity and measured concentrations of $\mathrm{CO}_{2}$.

Flux series were screened for the detection of anomalous values arising from sensors malfunctioning caused in particular by interference of water condensation, rain drops or insects with the optical path of the IRGA. Fluxes associated to $\mathrm{CO}_{2}$ concentrations out of the typical range of values for the site or to variance of the $30 \mathrm{~min}$ signal of $\mathrm{CO}_{2}$ over the 97.5 percentile, were rejected.

Spikes remained in the half hourly dataset were detected by using an algorithm based on the position of each half hourly value with respect to the values just before and after. It is applied to blocks of 13 days and separately for daytime and nighttime data and it is based on the double-differenced time series, using the median of absolute deviation about the median (MAD) according to Papale et al. (2006) and using the z-values set to 5.5.

Data gaps included also rejected NEE values associated to low turbulence conditions (low $u_{*}$ ) which accounted for $15.1 \%$ of data. The $u_{*}$ threshold was defined according with Reichstein et al. (2005) and Papale et al. (2006) using a bootstrapping technique (100 sampling). The selected threshold value is the median of the 100 thresholds found and in this case is $0.06 \mathrm{~m} \mathrm{~s}^{-1}$. It is possible also to define an uncertainty or variability of the $u_{*}$ threshold looking to the distribution of the $100 u_{*}$ values obtained with the bootstrapping; in this application we assessed the annual NEE also filtering the data using $5 \%$ and $95 \%$ percentile values of $u_{*}$ threshold estimate (0.04 and $0.085 \mathrm{~m} \mathrm{~s}^{-1}$, respectively).

Gaps totalized $30.1 \%$ of data series, $1.4 \%$ being due to IRGA maintenance and calibration, power outages and blockage of the system and the remaining $28.7 \%$ to removal of spikes, bad quality data and fluxes associated to low turbulence conditions.

To assess the accuracy of eddy covariance measurements, we analyzed the linear regression between the sum of sensible heat $(\mathrm{H})$ and latent heat $(\mathrm{LE})$ versus the difference of net radiation $(\mathrm{Rn})$ and soil heat flux $(\mathrm{G})$ based on half hourly data:

$H+L E=a_{0}+a_{1}\left(R_{n}-G\right)$

obtaining a closure of the energy balance of $0.78(a)$, an intercept of $7.9\left(a_{0}\right)$ with $\mathrm{R}^{2}=0.91$.

Before data gapfilling, NEE was computed correcting $\mathrm{Fc}$ for the $\mathrm{CO}_{2}$ storage term (Fst, $\mu \mathrm{mol} \mathrm{CO} \mathrm{Cm}^{-2} \mathrm{~s}^{-1}$ ), based on the one point $\mathrm{CO}_{2}$ concentration from the open-path IRGA of the eddy covariance system, as in (Flanagan et al., 2002):

$\mathrm{Fst}=\frac{\rho_{a} h \Delta C}{\Delta t}$

where $\rho_{a}$ is air molar density $\left(\mathrm{mol} \mathrm{m}^{-3}\right), h$ is the height of the column of air up to the level of the IRGA $(\mathrm{m}), \Delta C$ is the change in $\mathrm{CO}_{2}$ concentration $\left(\mathrm{mmol} \mathrm{mol}^{-1}\right)$ and $\Delta t$ is the change in time (s).

In absence of $\mathrm{a} \mathrm{CO}_{2}$ profile system, this approach might be acceptable because storage term sums tend to zero on daily $\left(-3.8 \times 10^{-3} \mathrm{~g} \mathrm{C} \mathrm{d}^{-1}\right)$ and seasonal time scale (Baldocchi, 2003; Anthoni et al., 1999).

\subsubsection{Gapfilling}

The gapfilling procedure was performed applying separately three techniques, for the purpose of comparing their effect on the result of the carbon balance: (1) non-linear regressions (Falge et al., 2001), (2) Marginal Distribution Sampling (MDS) method (Reichstein et al., 2005) and artificial neural networks (ANN) (Papale and Valentini, 2003)

\subsubsection{Non linear regressions.}

Missing data at daytime (PPFD $>0$ ) were filled by using rectangular hyperbolic light response functions (Falge et al., 2001) fitted to Fc for 15 days time windows:

$\mathrm{NEE}=\frac{F_{\max } \alpha Q_{p}}{\alpha Q_{p}+F_{\max }}+R_{\mathrm{eco}}$

where $Q_{p}$ is the incident photosynthetically active radiation $\left(\mu \mathrm{mol} \mathrm{m}{ }^{-2} \mathrm{~s}^{-1}\right), F_{\max }\left(\mu \mathrm{mol} \mathrm{m}{ }^{-2} \mathrm{~s}^{-1}\right)$ is the maximum $\mathrm{CO}_{2}$ flux at infinite light, $\alpha$ the apparent quantum yield and $R_{\text {eco }}$ the ecosystem respiration.

Night-time gaps according to the non-linear regression method were filled by using exponential relationships, retrieved for 1 month time windows, between night-time NEE sorted by periods of high turbulence $\left(u_{*}>=0.06 \mathrm{~ms}^{-1}\right)$ and soil temperature (Tsoil) measured at $10 \mathrm{~cm}$ depth:

$\mathrm{NEE}_{\text {night }}=R_{\mathrm{eco}}=a \exp ^{\mathrm{bTsoil}}$

where $a$ and $b$ are empirical coefficients. 


\subsubsection{Marginal Distribution Sampling}

In the application of MDS method, given the fact that meteorological data were available without gaps, missing values of NEE were replaced by average values under similar meteorological conditions within a time window of \pm 7 days. Similar meteorological conditions are present when global radiation $\left(R_{g}\right), T_{\text {air }}$ and VPD do not deviate by more than $50 \mathrm{~W} \mathrm{~m}^{-2}$, $2.5^{\circ} \mathrm{C}$ and $5.0 \mathrm{hPa}$, respectively. If no similar conditions were present within the time window the averaging window was increased and similar conditions were defined only based on $\mathrm{Rg}$ or simply the measurement time (see Reichstein et al., 2005 , for details).

\subsubsection{Artificial Neural Networks}

The feed-forward backpropagation artificial neural networks (ANNs) are non-linear data based models able to reproduce continuous non-linear functions. The relations between input and output variables are found using training algorithms and a dataset of real observations (Papale and Valentini, 2003). After the training phase the ANN can be applied to other cases starting only from the input values, showing a good generalization capacity.

For this application the ANN have been trained using as input meteorological data (air temperature, photosynthetic photon flux density, air humidity) and the [sin] and [cos] operators of the julian day for the seasonal pace, while the output was the eddy covariance NEE measurements. The examples selected for the ANN training were only the half hourly data collected at Hak 1 site in 2004 under good conditions (after spike removing and $u_{*}$ filtering) and where all the input variables were available. The trained ANN have been then applied to the half hours where the input were available but the output missing.

\subsubsection{Flux partitioning}

The partitioning of NEE into the component of GPP was then obtained as:

$\mathrm{GPP}=R_{\mathrm{eco}}-\mathrm{NEE}$

Where the ecosystem respiration, $R_{\text {eco }}$, was obtained using the two following approaches:

1) Extrapolating daytime ecosystem respiration from temperature response functions used for gapfilling of night-time NEE according to the non linear regression method.

2) Applying the algorithm by Reichstein et al. (2005), that derives a short-term temperature sensitivity of $R_{\text {eco }}$ from eddy covariance data based on the exponential regression model (Lloyd and Taylor, 1994):

$R_{\mathrm{eco}}=R_{\mathrm{ref}} e^{E_{0}\left(1 /\left(T_{\mathrm{ref}}-T_{0}\right)-1 /\left(T-T_{0}\right)\right)}$

Regressions were performed for subperiods of 15 days, with consecutive time windows overlapping 10 days, in order to estimate the temperature sensitivity parameter $E_{0}$, setting the reference temperature to $10^{\circ} \mathrm{C}$ and keeping constant the parameter $T_{0}$ at $-46.02^{\circ} \mathrm{C}$ as in Lloyd and Taylor (1994). After an $E_{0}$ parameter representative for the whole monitoring period was estimated, the temperature independent level of respiration $\left(R_{\text {ref }}\right)$ was estimated for consecutive 4 days periods by non-linear regression using the Lloyd and Taylor model, fixing all parameters except $R_{\text {ref. }} R_{\text {ref }}$ parameters estimated were assigned to the "centre of gravity" of the data of each period and were then linearly interpolated between the estimates producing a continuous time series.

\subsection{Soil $\mathrm{CO}_{2}$ fluxes}

Soil respiration was measured weekly using a closed dynamic system (EGM2, PP Systems, UK) over 10 plots selected within the footprint area along N-S and W-E directions and spaced out of $30 \mathrm{~m}$, where PVC collars (diameter $10 \mathrm{~cm}$; height $6 \mathrm{~cm}$ ) were inserted approximately $3 \mathrm{~cm}$ deep in the ground. Collars were located in the space between graminoids tussocks and the possible live stems within the surface inscribed by the collar were clipped to avoid measuring $\mathrm{CO}_{2}$ fluxes originated else than from the soil.

Heterotrophic component of soil respiration flux was measured at weekly frequency applying two variants of the root exclusion method (root removal and trenching) over 6 additional plots whose dimensions were $(40 \times 40) \mathrm{cm}$ by $30 \mathrm{~cm}$ of depth, adjacent to the plots located along the W-E direction. In three of these plots the extracted soil was cleaned from roots and was placed back into each pit and further root growth was prevented by barriers placed on the lateral faces; while in the remaining three plots, roots were severed by trenching but not removed, and barriers were installed to inhibit future root growth. Regrowth of grass from germination in the plots was inhibited by frequent checks of the experimental area and removal of seedlings found. To address the problem of the influence of residual decomposing roots left in the trenched plots over soil $\mathrm{CO}_{2}$ efflux rates, we allowed 12 months to pass after trenching before collecting soil $\mathrm{CO}_{2}$ efflux data. No significative difference was observed $(\alpha=0.05)$ in soil $\mathrm{CO}_{2}$ effluxes (two-tailed T-test: $P T<t 0.17$ ) nor soil temperature (two-tailed T-test: $\mathrm{P} T<t 0.79$ ) between plots with the result being independent of the technique applied.

Further measurements of $\mathrm{CO}_{2}$ effluxes, aimed at monitoring night-time ecosystem respiration by an alternative method to eddy covariance, were performed using a cuvette with diameter of $150 \mathrm{~mm}$ and height of $140 \mathrm{~mm}$ (CPY-2, PP Systems, UK) connected to the EGM2, designed to allow for closed system measurement of $\mathrm{CO}_{2}$ fluxes in low plant canopies and soil. Measurements were taken over eight plots located close to the PVC collars aligned along the W-E direction, inserting the cuvette in the soil by the sharpened metal rim at its base and enclosing the canopies within the cuvette's volume. 


\subsection{Net ecosystem production}

Net ecosystem production was assessed by two independent methods: (i) micrometeorologial approach (eddy covariance technique) as the summation of carbon dioxide fluxes averaged on half hourly basis over the whole period of monitoring and (ii) by ecological inventory by which NEP is retrieved as follows:

$\mathrm{NEP}=\mathrm{NPP}-R h$

where NPP is net primary productivity and Rh is the heterotrophic component of the soil respiration cumulated over the monitoring period.

2.7 Uncertainty analysis in inventory and eddy covariance based estimates of NEP

The uncertainties of biometric and of soil $\mathrm{CO}_{2}$ fluxes measurements associated only to sampling errors, not accounting for systematic errors arising for instance from instruments readings, were calculated as $95 \%$ confidence interval around the mean value of each set of measurements; the uncertainty of NPP assessment and of the cumulated value of heterotrophic respiration were computed applying the following rules for combining uncertainties by addition (1) and multiplication (2) (IPCC, 2000):

(1)

$U_{\text {total }}=\frac{\sqrt{\left(U_{1} x_{1}\right)^{2}+\left(U_{2} x_{2}\right)^{2}+\ldots+\left(U_{n} x_{n}\right)^{2}}}{x_{1}+x_{2}+\ldots+x_{n}}$

(2)

$U_{\text {total }}=\sqrt{U_{1}^{2}+U_{2}^{2}+\ldots+U_{n}^{2}}$

where:

$U_{\text {total }}$ is the percentage uncertainty in the sum of the quantities (half the $95 \%$ confidence interval divided by the total (i.e. mean) and expressed as a percentage); $x_{i}$ and $U_{i}$ are the uncertain quantities and the percentage uncertainties associated with them, respectively.

Estimates of uncertainty in eddy covariance $\mathrm{CO}_{2}$ fluxes, arising from the accumulation of either random instrument errors and systematic errors of various kinds, were addressed following Ehman et al. (2002). Considering the measurement uncertainty of hourly eddy covariance fluxes as $30 \%$, and that the daily NEE values derive from the sums of hourly $\mathrm{CO}_{2}$ fluxes measurements, we calculated the random error in the mean flux for one mean daily cycle as Goulden et al. (1996):

$E r=p r \sqrt{\frac{\sum_{i=1}^{N}(F i)^{2}}{N}}$

Where $p r$ is the random error (\%) applied to each half-hour data, $\mathrm{N}$ is the number of flux measurements in one day (48), and $F i$ is the $i$-th flux measurement of the daily cycle. The combined effect of random errors over NEE estimate decays with the square root of the number of summands, such that $\operatorname{Er}(N d)=E r / \sqrt{N d}$ where $N d$ is the number of days. Being the magnitude and sign of systematic errors unknown and given the systematic error on one mean diurnal cycle as the sum of the individual systematic errors

$E s=p s \sum_{i=1}^{N} F i$

where $p s$ is the systematic error (\%).We only allowed $50 \%$ of the standard random cancellation of half hourly errors on daily totals of NEE and no cancellation in the accumulation of daily totals on long term NEP. The assessment of uncertainties of NEP for the whole period was completed with the quantification of errors deriving from the gapfilling procedure and with the analysis of sensitivity of the cumulated NEP versus the $u_{*}$. The first included the deviation of results yielded by the application of the different gapfilling techniques and the uncertainty stemming from the application of the gapfilling techniques which was taken into consideration by referring to the results found by Moffat et al. (2007) ${ }^{1}$ where different gapfilling methods have been compared based on artificial gaps with different length and position. In that analysis, the three gapfilling methods used in this paper, have been applied to 10 different yearly datasets from 6 forest sites.

The sensitivity of NEP in respect with $u_{*}$ was analyzed selecting an interval between the $5 \%$ and $95 \%$ percentile values of $u_{*}$ threshold estimate ( 0.04 and $0.085 \mathrm{~m} \mathrm{~s}^{-1}$, respectively). The restriction of such analysis to a particular range of $u_{*}$ is justified by the intention of evaluating the uncertainty of the NEP assessment related to the selection of a determined $u_{*}$ threshold within a valid range, and excludes therefore lower $u_{*}$ values for which the overestimation of the NEP would be obvious (Barford et al., 2001).

\section{Results}

\subsection{Biomass dynamics and assessment of NPP}

At the date of the first biomass sampling (1 May), the growing season had still not begun, as evidenced by the absence of live aboveground biomass (Fig. 1a). The dead aboveground biomass was $0.39 \mathrm{td} . \mathrm{m} . \mathrm{ha}^{-1}$, a value by far lower than the typical amount of dry grass in spring recorded during previous campaigns at the same site, because the steppe was run by a fire in March 2004, which nevertheless burnt the grass stems and affected moderately the amount of litter in the area. The peak of aboveground live biomass was reached in the

\footnotetext{
${ }^{1}$ Moffat, A., Papale, D., Reichstein, M., et al.: Comprehensive comparison of gap filling techniques for eddy covariance net carbon fluxes, Agricultural Forest Meteorology, submitted, 2007.
} 


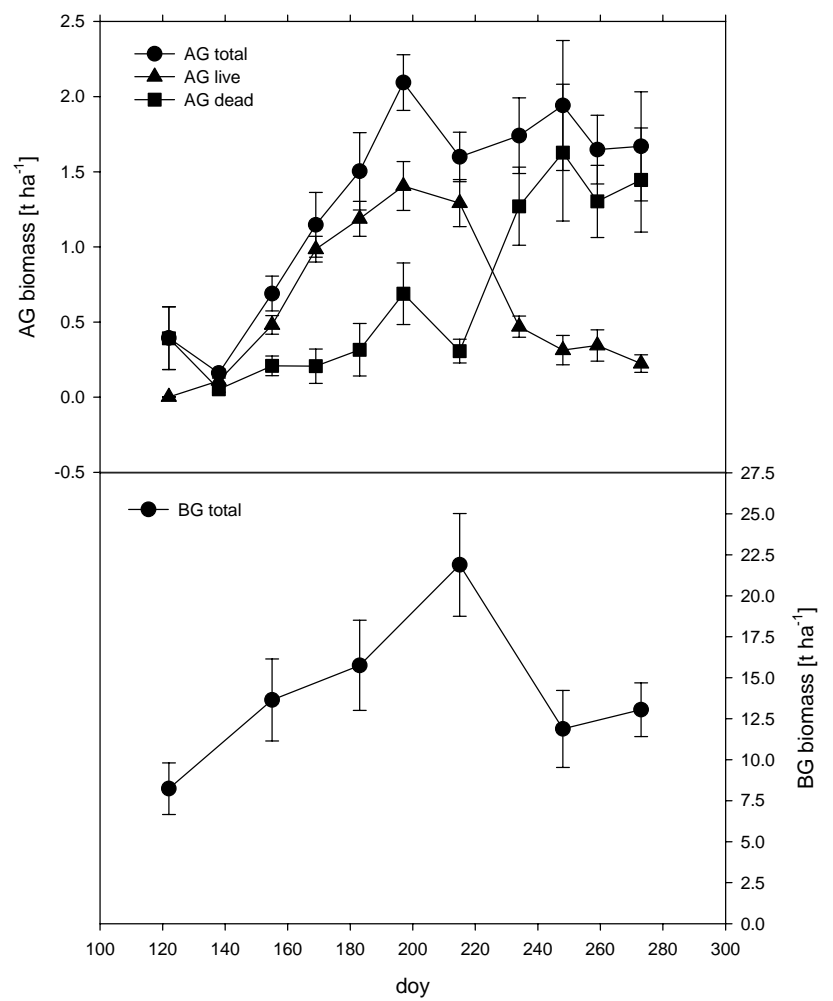

Fig. 1. (a) trend of aboveground biomass sorted into live and dead; (b) trend of belowground biomass including live and dead biomass. Error bars indicate the $95 \%$ confidence interval.

middle of July with $1.40 \mathrm{t}$ d.m. ha ${ }^{-1}$ that corresponded also to the peak of total aboveground biomass $\left(2.09 \mathrm{td}\right.$ d.m. ha $\left.{ }^{-1}\right)$; After this stage the quantity of aboveground biomass remained substantially steady as the decrease of living biomass since the second half of August, associated to the beginning of the senescence phase, was compensated by the increase in dead biomass. In September however there was a new sprout of grass which is visible in the sustained level of live AG biomass after its previous rapid decline. The comparative analysis of the trend of live and dead aboveground biomass from May to July reveals their synchronous increase, which apart from being the evidence of mortality induced by intra and inter-specific competition is also determined by the overlapped development phases of different kind of grass cenosis along the growing season.

The amount of belowground biomass ranged between $88 \%-95 \%$ of total biomass along the monitoring period (Fig. 1b) and it was characterised by the same growth pattern of AG biomass from May to August, reaching its peak on the sampling of 1 August (doy 214) $\left(21.8 \mathrm{td}\right.$.m. ha $\left.{ }^{-1}\right)$. Before August roots biomass decreased significantly as an evidence of the intense decomposition activity, while in September a new increment attributable to a late seasonal sprout of root productivity before winter senescence was recorded. It seems reasonable to doubt that the fire occurred during win-

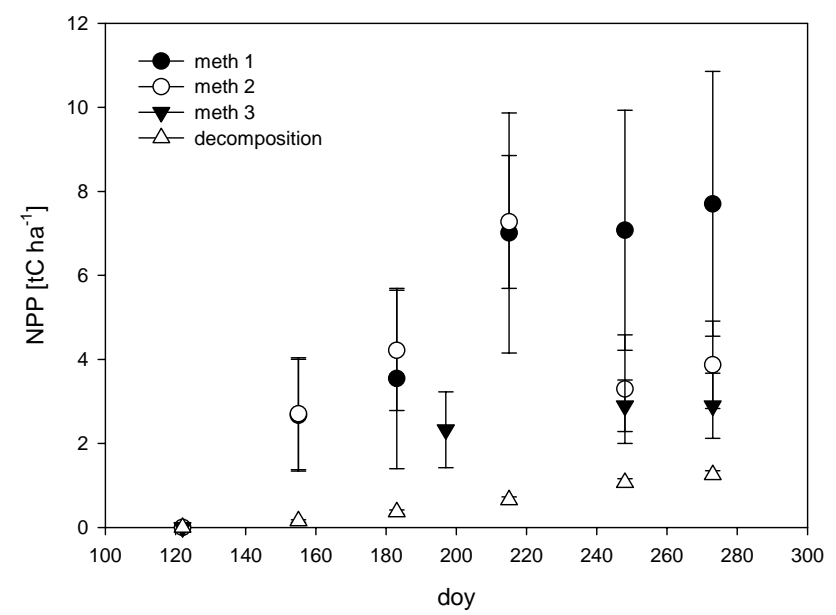

Fig. 2. NPP assessed by three methods (black dots: sum of positive changes in biomass; white dots: sum of changes in biomass with adjustment for decomposition; black triangles: sum of positive changes in AG biomass and BG-NPP assessed by ingrowth cores) along the biomass sampling dates of the growing season. Amount of dead biomass decomposed (white triangles). Error bars indicate the $95 \%$ confidence interval of the estimate based exclusively on the propagation of sampling errors.

ter burnt part of the belowground biomass because the difference in the quantity of roots, collected in the root ingrowth cores at the end of the previous growing season (15 October 2003) and at the beginning of May 2004, respectively, likely depended on the sole process of decomposition $(\approx-40 \%)$.

The assessment of NPP for the whole period of observations (May-September) varied sensibly depending on the method used (Fig. 2): method 1 (sum of positive increments of AG and BG biomass) led to $7.70 \pm 3.15 \mathrm{t} \mathrm{C} \mathrm{ha}^{-1}$ (95\% confidence limit); method 2 (sum of changes in AG and BG biomass with adjustment for decomposition) led to $3.87 \pm 1.03 \mathrm{t} \mathrm{C} \mathrm{ha}^{-1}$ while according to method 3 (sum of positive increments in AG biomass; BG NPP determined by roots growth within ingrowth cores) the NPP was $2.89 \pm 0.77 \mathrm{t} \mathrm{C} \mathrm{ha}^{-1}$. The averaged assessment of NPP was therefore $4.82 \pm 1.65 \mathrm{t} \mathrm{C} \mathrm{ha}^{-1}$. The proportion of NPP allocated belowground was $87 \%, 84 \%$ and $71 \%$ according to methods 1, 2 and 3, respectively (Fig. 3).

Methods 1 and 2 differ only by the term of decomposition until the total biomass reaches the maximum, after that the assessment of NPP provided by method 2 drops because the decline in belowground biomass in August is not traded off by the estimation of the amount of decomposed biomass in that period. The divergence in the results of the two methods is thus likely due to the underestimation of the carbon lost in the process of decomposition which is most intense during summer months because of favourable conditions such as high temperatures and precipitation. Total modelled decomposition is equal indeed to $1.25 \pm 0.1 \mathrm{t} \mathrm{C} \mathrm{ha}^{-1}$ for the 


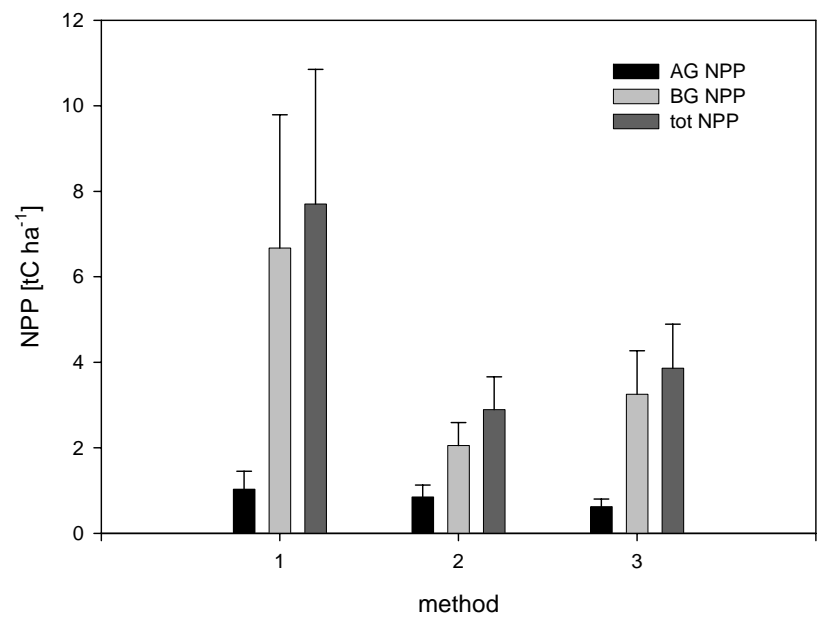

Fig. 3. Above ground (AG), Belowground (BG) and total NPP assessed according to methods applied.

period from May to September, which corresponds only to $16 \%$ and $31 \%$ of NPP estimated with method 1 and 2, respectively. Although the extrapolation of the estimate of amount of decomposed matter for a whole year would lead to a substantially sensible result (since the model is parameterized on the base of annual rates of biomass decomposition of central Asian steppes), decomposition rates can be significantly different over limited time windows leading to underestimate (during summer) NPP when applying method 2. On the other hand method 1 tends to overestimate systematically the real NPP (Scurlock et al., 2002) because it incorporates in the sum only terms associated to a positive change in biomass, although they can be related to the effect of sampling error and not to a real increase in primary productivity. Contrary to the methods 1 and 2, method 3 does not keep track of the increment in biomass in September leading to the lowest estimate of NPP with the lowest root-shoot ratio. The possibility of simultaneous growth and decomposition of root biomass within the ingrowth cores, as it likely happened at the end of the summer, is the main flaw of this method and leads to an underestimation of the belowground primary productivity. In spite of this, method 3 is the only one that allows to limit the magnitude of the uncertainty of NPP assessment by measuring directly the increments in biomass and not to deduce them by differences in biomass stocks.

\subsection{Soil $\mathrm{CO}_{2}$ fluxes}

Soil respiration fluxes measured by chambers responded to soil temperature according to a linear relation ( $\mathrm{SR}=0.22$ (Tsoil) $-0.42 ; \quad R^{2}=0.88 ; \mathrm{n}=23$ ). Values ranged from a minimum of 0.64 and $0.24 \mu \mathrm{molCO}_{2} \mathrm{~m}^{-2} \mathrm{~s}^{-1}$ in the beginning of May and in the end of September, respectively, to a maximum of $4.3 \mu \mathrm{molCO}_{2} \mathrm{~m}^{-2} \mathrm{~s}^{-1}$ in middle July (Fig. 4). Heterotrophic fraction of soil respiration repre-

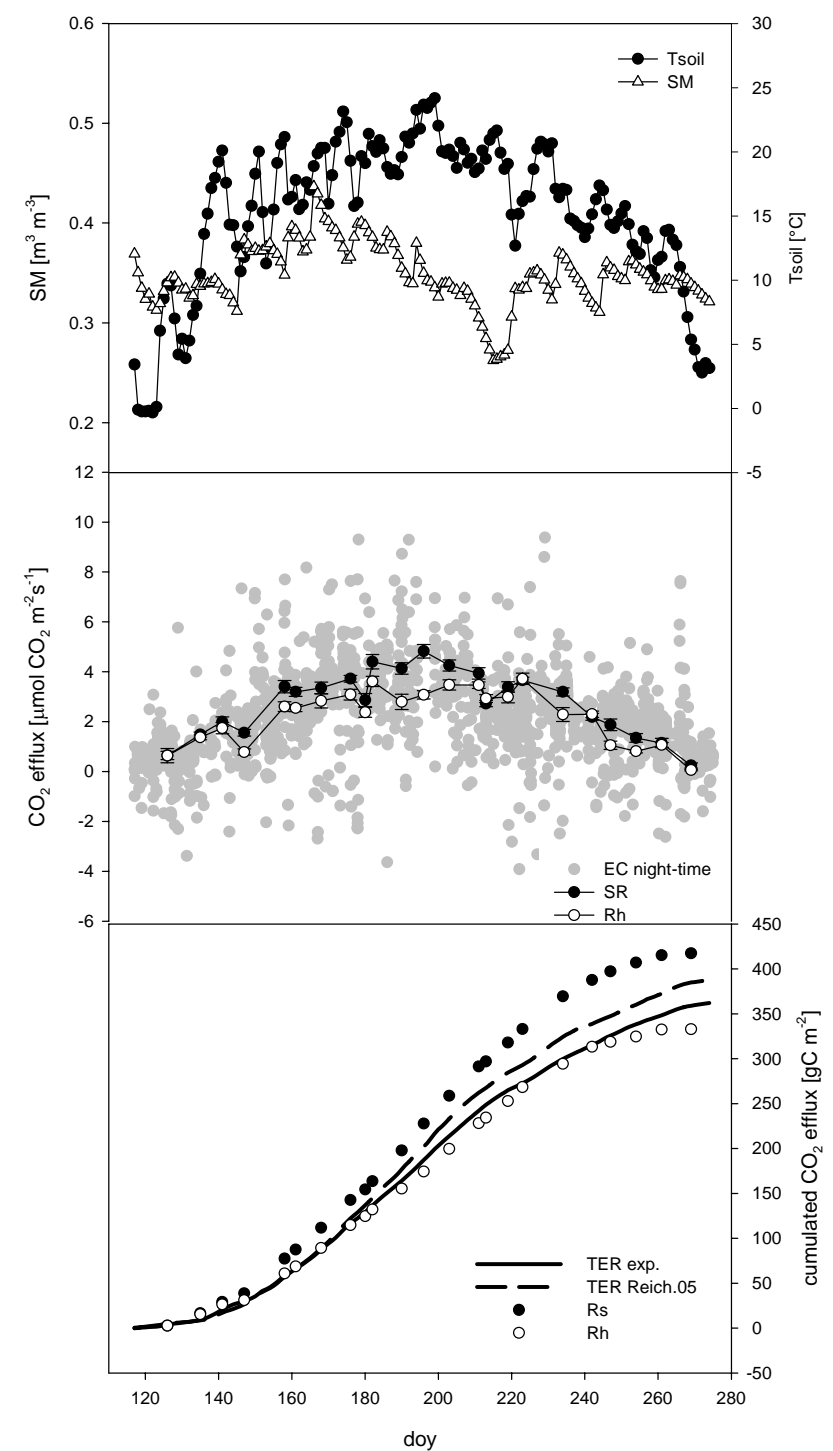

Fig. 4. Above: trend of daily average of soil temperature $(-5 \mathrm{~cm})$ (black dots) and soil moisture (white triangles). Middle: trend of soil respiration (black dots) and heterotrophic component of soil respiration (open dots) measured by chamber technique (error bars: \pm standard error), total ecosystem respiration by eddy covariance (grey dots) measured during night-time; Below: trend of cumulated ecosystem respiration modelled with exponential model (lower solid line), with Reichstein et al. (2005) model (upper dashed line); cumulated soil respiration (Rs) (black dots) and heterotrophic respiration $(\mathrm{Rh})$ (white dots).

sented almost the whole soil $\mathrm{CO}_{2}$ efflux in early May before the onset of vegetation and was also linearly correlated to the soil temperature $\left(\mathrm{Rh}=0.17\right.$ (Tsoil) $\left.-0.18 ; \mathrm{R}^{2}=0.72\right) . \quad \mathrm{Rh}$ values reached maximum values in the time window between end of June and beginning of August (2.79-3.71 $\mu \mathrm{mol}$ $\mathrm{CO}_{2} \mathrm{~m}^{-2} \mathrm{~s}^{-1}$ ) when $\mathrm{Rh}$ represented in average about $68 \%$ of soil respiration. The autotrophic component of soil $\mathrm{CO}_{2}$ 


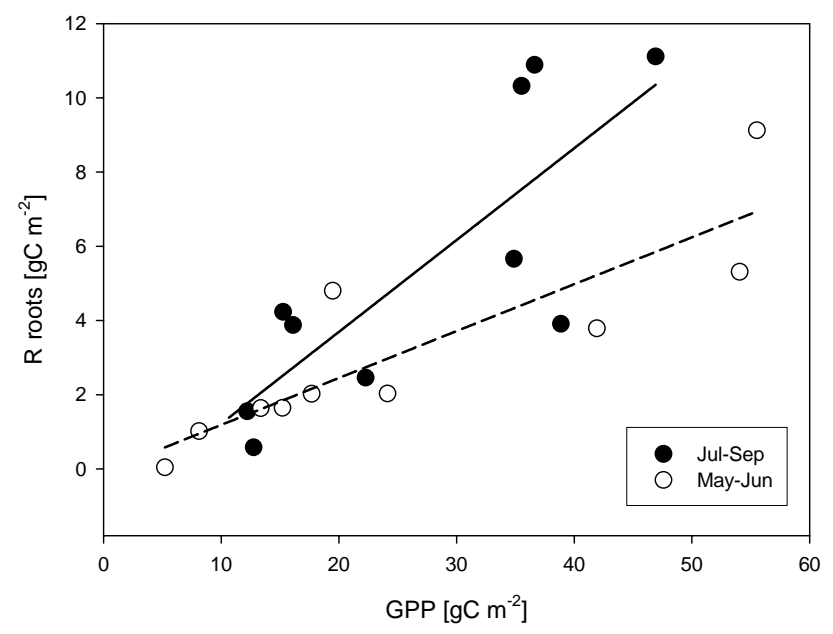

Fig. 5. Relation between root respiration (R roots) and gross primary productivity (GPP) cumulated over the periods between measurements assuming linear variation of root respiration within each period. The linear regression for the early summer (white dots, dashed line) gives a slope of $0.12\left(P<0.01, r^{2}=0.75\right)$ while for the late summer (black dots, solid line) the ratio of $R$ roots/GPP is 0.24 $\left(P>0.01, r^{2}=0.64\right)$.

effluxes, retrieved as the difference between measurements of soil respiration and its heterotrophic fraction, was greater during periods of biomass growth, (from 1.34 to $1.75 \mu \mathrm{mol}$ $\mathrm{CO}_{2} \mathrm{~m}^{-2} \mathrm{~s}^{-1}$ in late July). In general, the magnitude of root respiration, cumulated for each time interval between measurements, was proportional to the photosynthetic activity, albeit with considerable scatter $(\mathrm{R} a=0.16 \mathrm{GPP}-0.15$; $R^{2}=0.56 ; \mathrm{n}=20$ ); however it is possible to reduce substantially the scatter of this relation by analyzing the response to gross primary productivity only for the periods from May to July $\left(R^{2}=0.75\right)$ (Fig. 5), as during the remaining part of the season the values of root respiration associated to lower levels of photosynthesis suggest that the support for root respiration was provided mostly at the expenses of the plants reservoirs of carbon, possibly from the translocation of carbon from the aboveground to the belowground biomass.

Using a linear interpolation of soil fluxes between measurements dates, the cumulated value of soil respiration for the whole monitoring period, was $417.2 \mathrm{~g} \mathrm{C} \mathrm{m}^{-2}$ partitioned into $332.7 \mathrm{~g} \mathrm{C} \mathrm{m}^{-2}$ (79\%) from heterotrophic respiration and $84.5 \mathrm{~g} \mathrm{C} \mathrm{m}^{-2}$ (21\%) from autotrophic origin (Fig. 4).

3.3 Comparison between eddy covariance system and chamber based measurements of total ecosystem respiration

Ecosystem respiration measured by chamber CPY2 was up to six fold greater than the correspondent measured values by eddy covariance when friction velocity was below the threshold of $0.06 \mathrm{~m} \mathrm{~s}^{-1}$, confirming the failure of the E.C. system

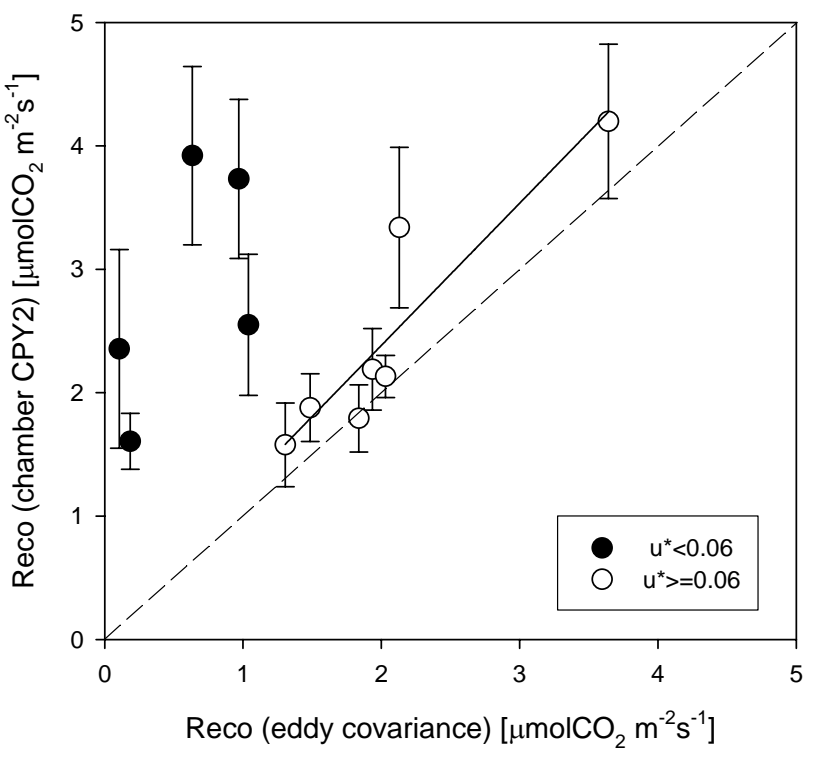

Fig. 6. Comparison of eddy covariance and chamber based measurements of ecosystem respiration for conditions of friction velocity above $0.06 \mathrm{~ms}^{-1}$ (white dots) with linear regression (solid line) and below $0.06 \mathrm{~ms}^{-1}$ (black dots). Errors bars stand for standard error of chamber $\mathrm{CO}_{2}$ flux measurements.

in measuring the whole magnitude of night-time fluxes in conditions of low atmospheric turbulence (Fig. 6). Nevertheless, sorting the chamber measurements taken when $u_{*}$ was greater than $0.06 \mathrm{~ms}^{-1}$, the comparison between the two techniques evidences a fairly good match of ecosystem respiration values with chamber based fluxes being on average still higher than eddy covariance measurements (Reco(CPY2) $=1.15$ Reco $(\mathrm{EC})-0.07 ; R^{2}=0.83 ; \mathrm{n}=7$ ): differences in fluxes did not overcome $1.21 \mu \mathrm{mol} \mathrm{CO}_{2} \mathrm{~m}^{-2} \mathrm{~s}^{-1}$ and were limited in the range $-2 \%-+36 \%$ in respect with the eddy covariance measurements.

\subsection{Eddy covariance measurements}

During the first two weeks of May the ecosystem was a small source of carbon with mean daily NEP values of about $0.08 \mathrm{~g}$ $\mathrm{C} \mathrm{m}^{-2} \mathrm{~d}^{-1}$ : in this period daily NEP ranged widely between -0.41 and $1.42 \mathrm{~g} \mathrm{C} \mathrm{m}^{-2} \mathrm{~d}^{-1}$ and it was modulated by pronounced fluctuations in air temperature controlling respiratory activity while the vegetative season was on setting (Fig. 7). After 15 May (doy 136), carbon assimilation increased due to the start of the growing season induced an uptake of $\mathrm{CO}_{2}$ which rapidly reached its maximum $(-3.59 \mathrm{~g}$ $\mathrm{C} \mathrm{m}^{-2} \mathrm{~d}^{-1}$ the 9 June - doy 161) and kept sustained with a daily average of $-2.15 \mathrm{~g} \mathrm{C} \mathrm{m}^{-2} \mathrm{~d}^{-1}$ throughout the month of June. From July the daily NEP values started declining yet denoting a sink activity throughout the month August, with GPP slightly higher than TER, with a resulting daily average NEP of -1.41 and $-0.63 \mathrm{~g} \mathrm{C} \mathrm{m}^{-2} \mathrm{~d}^{-1}$ in the months of July 


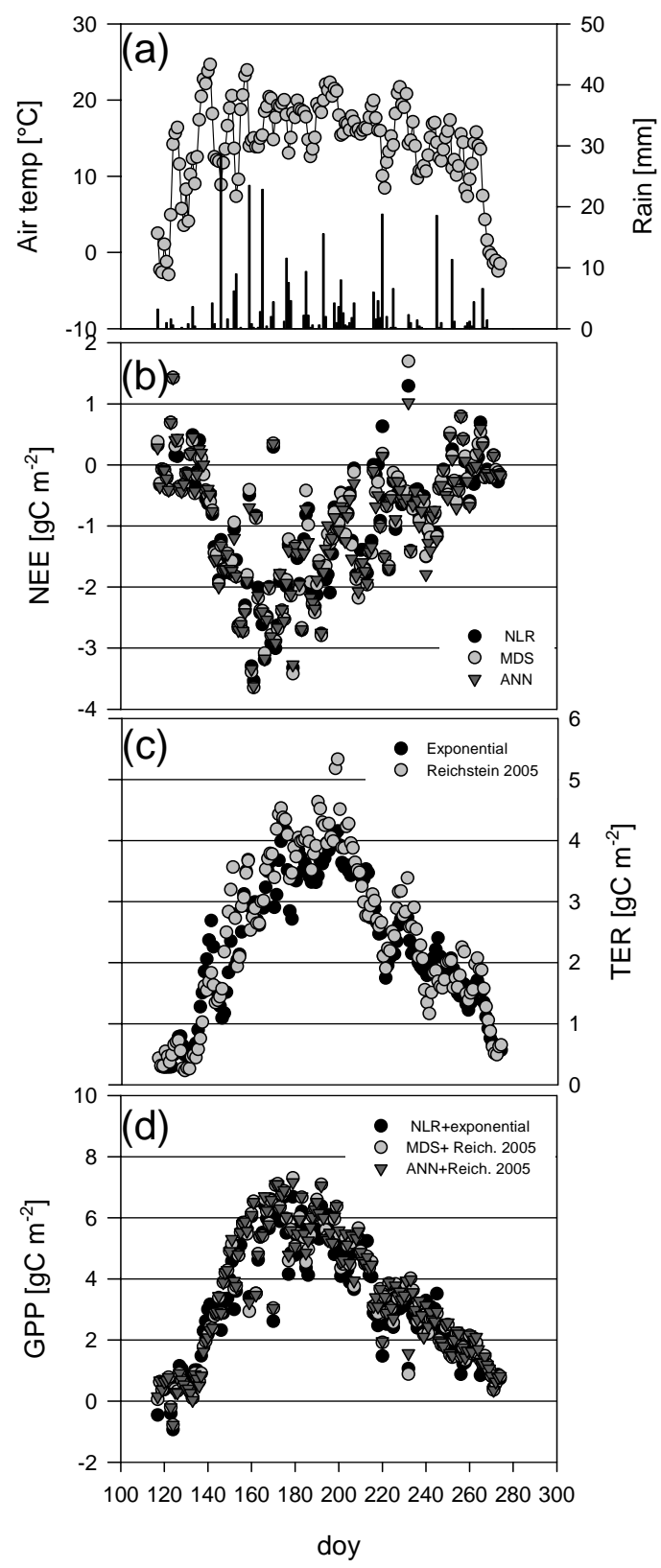

Fig. 7. (a): trend of daily average air temperature (grey dots) and precipitation (black bars). (b): trend of daily NEE gapfilled with NLR, MDS and ANN methods. (c) trend of daily TER modelled with simple exponential relations and Reichstein et al. (2005) algorithm. (d) daily GPP obtained as difference between: 1. NEE gapfilled with non linear regression method and TER modelled with simple exponential relations; 2. NEE gapfilled with MDS method and TER modelled according to Reichstein et al. (2005); 3. NEE gapfilled with ANN method and TER modelled as in Reichstein et al. (2005).

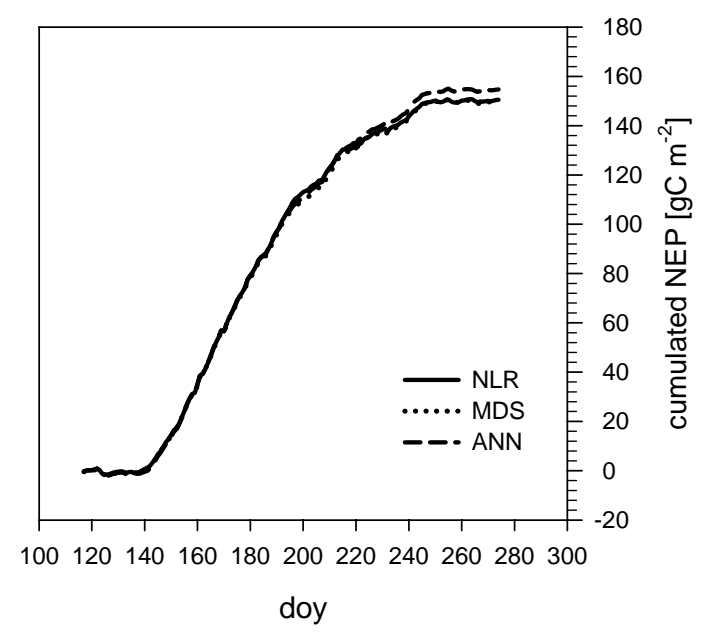

Fig. 8. Cumulated NEP with gaps filled by non linear regressions method (solid line), MDS (dotted line), ANN (dashed line).

and August, respectively. The magnitude of both respiratory and photosynthetic $\mathrm{CO}_{2}$ fluxes reduced further in September, when average daily NEP was $-0.05 \mathrm{~g} \mathrm{C} \mathrm{d}^{-1}$ and until, in the last week of September both GPP and TER dropped to $\pm 0.8 \mathrm{~g} \mathrm{C} \mathrm{m}^{-2} \mathrm{~d}^{-1}$ leading to a net flux close to zero.

The cumulated NEP over the period 26 April-30 September was $150.5,149.8$ and $154.7 \mathrm{~g} \mathrm{C} \mathrm{m}^{-2}$ according to the methods of gapfilling of non linear regression, MDS and ANN (average of NEP assessments: $151.7 \mathrm{~g} \mathrm{C} \mathrm{m}^{-2}$ ). (Fig. 8). The deviation in results of NEP obtained was $4.9 \mathrm{~g}$ $\mathrm{C} \mathrm{m}^{-2}$ representing $0.3 \%$ of average cumulated NEP, while the mean uncertainty in the annual carbon budget stemming from the application of the three different gapfilling techniques was quantified in $5.3 \mathrm{~g} \mathrm{C} \mathrm{m}^{-2}$.

NEP estimate showed an average increase of $6.7 \mathrm{~g} \mathrm{C}$ $\mathrm{m}^{-2}$ when $u_{*}$ threshold was set to $0.04 \mathrm{~ms}^{-1}$, which was more pronounced when gapfilling with non linear regression method $\left(7.2 \mathrm{~g} \mathrm{C} \mathrm{m}^{-2}\right)$ and less applying the ANN method $\left(6.3 \mathrm{~g} \mathrm{C} \mathrm{m}^{-2}\right)$, while at the upper limit $\left(u_{*}=0.085 \mathrm{~ms}^{-1}\right) \mathrm{NEP}$ decreased on average by $-6.6 \mathrm{~g} \mathrm{C} \mathrm{m}^{-2}$ (Fig. 9). The weight of uncertainty over NEP estimate dependent on the $u_{*}$ threshold selection can thus be approximated as $\pm 4.4 \%$.

The overall assessment of the uncertainty of the carbon budget retrieved by eddy covariance measurements was $\pm 36.9 \mathrm{~g} \mathrm{C} \mathrm{m}^{-2}$, that corresponds to $24 \%$ of the cumulated flux. The cumulated value of TER over the monitoring period, based on simple exponential relations between nighttime respiration and soil temperature, was $361.9 \mathrm{~g} \mathrm{C} \mathrm{m}^{-2}$ while adopting the model of Reichstein et al. (2005) it was $387.7 \mathrm{~g} \mathrm{C} \mathrm{m}^{-2}$ (average $374.8 \mathrm{~g} \mathrm{C} \mathrm{m}^{-2}$ ). The divergence of $25.8 \mathrm{~g} \mathrm{C} \mathrm{m}^{-2}$ between the two estimates of TER does not arise from systematic higher outputs by the model of Reichstein et al. (2005), while results of both models are respectively either higher and lower along the season without highlighting any particular systematic difference. The cumulated 
Table 1. Comparison of assessment of NEP by ecological inventory and eddy covariance approaches.

\begin{tabular}{llll}
\hline & $\begin{array}{l}\text { assessment } \\
{\left[\mathrm{g} \mathrm{C} \mathrm{m}^{-2}\right]}\end{array}$ & $\begin{array}{l}\text { uncertainty } \\
\pm\end{array}$ & remark \\
\hline 1. NPP & 482.8 & 165.5 & $(0.95$ confidence interval $)$ \\
2. Rh (heterotrophic respiration) & 332.7 & 105.2 & $(0.95$ confidence interval $)$ \\
3. NEP (ecological inventory) & 150.1 & 196.1 & $(0.95$ confidence interval $)$ \\
4. NEP (eddy covariance) & 151.7 & 36.9 & \\
$\Delta(4-3)$ & 1.6 & & $(1.0 \%$ of NEP $)$ \\
\hline
\end{tabular}

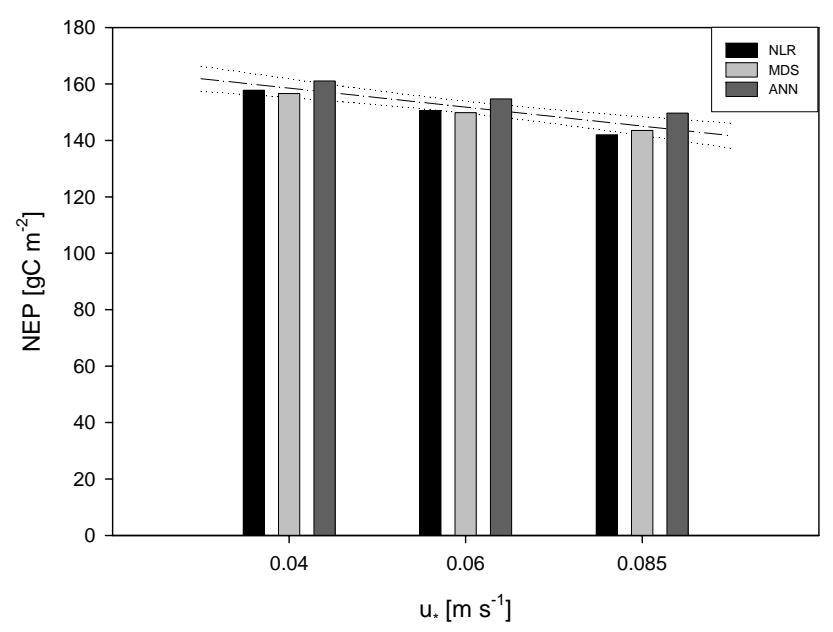

Fig. 9. Analysis of sensitivity of NEP, obtained with different gapfilling methods (NLR, MDS, ANN) versus the value of $u_{*}$ selected as threshold for rejection of night-time eddy covariance fluxes within a range of 0.04 and $0.085 \mathrm{~ms}^{-1}$ corresponding to the 5 th and 95th percentile of the results from the iterative procedure for $u_{*}$ threshold determination.

GPP over the same period was 512.5, 537.5 and 542.4 g C $\mathrm{m}^{-2}$ (average $530.8 \mathrm{~g} \mathrm{C} \mathrm{m}^{-2}$ ) obtained by difference of NEP gapfilled by non linear regression and TER modelled with simple exponential model, and by difference of NEP gapfilled with MDS, ANN methods and TER resulted from Reichstein et al. (2005) model. Total ecosystem respiration assessed by E.C. technique (taking into account chamber based measurements) consisted of $79 \%$ heterotrophic soil $\mathrm{CO}_{2}$ effluxes.

3.5 Comparison of carbon budget by ecological inventory and eddy covariance

The net ecosystem production assessed by the method of ecological inventory was $150.1 \pm 196 \mathrm{~g} \mathrm{C}$ where the uncertainty refers to the confidence interval of 0.95 (Table 1). This estimate was smaller than the NEP retrieved by the E.C technique by $1.6 \mathrm{~g} \mathrm{C}$ and the discrepancy of NEP assessment through the application of the two methods would be de- fined as negligible if compared with the results of the most favourable of similar works (Barford et al., 2001; Curtis et al., 2002; Ehman et al., 2002) which report differences between E.C and inventory based estimates of the carbon budget up to $30 \%$. However, the inventory based assessment suffers from a large uncertainty, more than 1.3 times the NEP, which makes not possible to clearly individuate the role of the steppe ecosystem as a carbon sink or source using this approach. Therefore, the inventory method, commonly used as a reference to compare the carbon balance assessment produced by flux measurements, shows in this study its own limitation in being a tight constraint.

\section{Discussion}

The amount of biomass measured during the seasonal monitoring is consistent with the numbers reported for the natural steppes of Hakasia (Titlianova et al., 2002): the biomass peak of $23.4 \mathrm{td} . \mathrm{m} . \mathrm{ha}^{-1}$ matches indeed the range of 18 26.5 reported for this kind of steppe. The great bulk of primary productivity is allocated in the belowground biomass and it therefore appears of crucial importance to monitor the dynamics of roots in order to reach fair assessments of NPP for these ecosystems; deriving belowground productivity through the application of a crude root-shoot ratio is not recommendable because the proportion of belowground productivity is subject to large interannual variations in response to mean summer temperature $(\mathrm{Ni}, 2004)$. The temporal resolution of the biomass monitoring should also be addressed in the sampling design for two main reasons: 1) the highly dynamic carbon turnover, especially in the root system, requires an adequate sampling frequency high enough to catch the increments of biomass which can be followed by periods of intense decomposition activity and 2) the growth of biomass that can take place during different phases of the growing season, such as roots growth in late summer, would not be taken into account by a scarce number of observations. It is then clear how the use of methods for the assessment of NPP based on single values of peak biomass can not be considered suitable for these kind of ecosystems, although very often they were adopted for this purpose given the general lack of data on biomass dynamics, 
particularly belowground (Scurlock et al., 2002; Ni, 2004). The remarkable difference in the results of NPP assessment depending on the methods applied has already been highlighted by a review on the subject (Scurlock et al., 2002) and this case study further confirms such findings(minimum $642 \mathrm{td}$.m. ha ${ }^{-1}$; maximum $1575 \mathrm{td}$ d.m. ha ${ }^{-1}$ ). However, the results obtained by various methods, with the exception of method 3 that is lower, fall within the range of NPP typical reported for natural steppes of temperate northern China and Central Asia. (730-2200)t d.m. ha ${ }^{-1}$ (Ni, 2004; Scurlock et al., 2002). Each NPP assessment method being characterized by biases whose magnitude and often sign are not known we envisage the necessity of following multiple methods, chosen according to the criterion of accounting for both trends of above and belowground biomass dynamics when data are available, and of providing an averaged estimate of NPP and the deviation among produced results. The shares of uncertainties in the assessments of belowground and aboveground NPP were $39.2 \%$ and $35.2 \%$, respectively; however, the belowground compartment, representing the largest fraction of biomass, is the source of an uncertainty in NPP more than 5 times larger than the aboveground one. In this study the average sampling error over all the sampling dates, with a number of 20 units per each sampling, was 19\% for aboveground and $18 \%$ for belowground biomass, at a level of significance of $95 \%$. We estimate the number of sampling units needed to lower the error to $10 \%$ as 54 for aboveground biomass and 58 for belowground: such number of samples would determine an uncertainty of 26\% in belowground NPP and 22\% in aboveground NPP.

The site, characterized by almost flat terrain (slope $2 \%$ along N-S direction) and by homogeneous vegetation cover far beyond the area of the footprint which during night-time and in conditions of developed turbulence $\left(u_{*}>0.1 \mathrm{~ms}^{-1}\right)$ extended on average to $725 \mathrm{~m}$ upwind from the sensors according to the model of Schuepp et al. (1990) offers in principle the requirements for the application of the eddy covariance technique without complications arising from the necessity of accounting for advective and flux divergence terms in order to produce defensible estimates of $\mathrm{CO}_{2}$ fluxes, as in the case of complex terrain sites (Baldocchi, 2003; Aubinet et al., 2003). Comparing the relative frequency of wind versus wind directions during night-time for conditions of low and high turbulence $\left(u_{*}<0.06 ; u_{*}>0.06\right)$ we did not detect any difference evidencing the presence of katabatic winds that could drain $\mathrm{CO}_{2}$ along the gentle slope during stable atmospheric conditions. Moreover the frequency of winds blowing along the slope of the terrain is only related to very few events ( $<2 \%$ of total distribution) and therefore the potential overall contribution of katabatic flows to the total flux is likely negligible. The analysis of night-time fluxes evidenced the underestimation of ecosystem respiration by eddy covariance during period with low turbulence: in case of $u_{*}<0.06$ we observed a correlation of $u_{*}$ with the $\mathrm{CO}_{2}$ fluxes. This result is confirmed also by independent chamber based mea- surements of ecosystem respiration being larger than eddy covariance based measurements when $u_{*}$ was under the selected threshold. This bias, widely observed in eddy covariance studies (Black et al., 1996; Goulden et al., 1996; Grace et al., 1996; Moncrieff et al. 1996; Mahli et al.,1998; Aubinet et al., 2000; Baldocchi et al., 2000) is corrected by replacing the underestimated effluxes in low wind conditions with fluxes modelled on the base of unbiased measurements taken over a certain threshold of friction velocity and represents reasonably a crucial issue for addressing an accurate assessment of the carbon budget. In this study we found that the variability of the NEP assessment arising from the selection of a determined $u_{*}$ threshold contributed to about $40 \%$ of the total uncertainty in the result and was of the same magnitude of the uncertainty originated from the selection of different gapfilling techniques.

\section{Conclusions}

Both eddy covariance and ecological inventory methodologies face significant difficulties, resulting in potential systematic biases of unknown magnitude or sign that are currently the subject of significant efforts in the ecological and the micrometeorological communities. This study is not intended to be an absolute validation of one methodology against the other and in the accurate evaluation of the uncertainties of each approach, but it tries to focus on the merits and flaws of each method providing a comparison of results of net ecosystem productivity for a specific environment, steppe plains, where it is possible to minimize the sources of errors for both methodological approaches. Our conclusions are the following:

1. The carbon balance of the monitored natural steppe showed, according to micrometeorological measurements, an uptake of carbon of $151.7 \pm 36.9 \mathrm{~g} \mathrm{C} \mathrm{m}^{-2}$, cumulated during the growing season from May to September. This result was in agreement with an independent estimate through ecological inventory which yielded a sink of $150.1 \mathrm{~g} \mathrm{C}\left(\Delta=1.6 \mathrm{~g} \mathrm{C} \mathrm{m}^{-2}\right)$ although this method was characterized by a large uncertainty $( \pm 130 \%)$ considering the $95 \%$ confidence interval of the estimate.

2. Eddy covariance measurements underestimated nighttime $\mathrm{CO}_{2}$ effluxes when friction velocity was below $0.06 \mathrm{~ms}^{-1}$ as evidenced also by the comparison with independent chamber based measurements of ecosystem respiration. To account for this bias measured fluxes under $u_{*}<0.06$ were rejected and replaced with modelled NEE: the sensitivity of the resulting NEP to the selection of the $u_{*}$ threshold, chosen within the 5th and 95th percentile of its estimate $\left(0.04-0.085 \mathrm{~ms}^{-1}\right)$, was quantified in $\pm 4.4 \%$. 
3. In a site whose conditions are considered suitable to perform unbiased eddy covariance flux measurements due to the missed capture of advective flux components, the multiple constrained assessment of NEP showed a fair match between the results of the techniques used.

4. Belowground processes in steppe ecosystems account for a pre-eminent part of the carbon exchange: in particular efforts to better quantify the dynamics of root biomass (growth and turnover) have to be undertaken in order to reduce the uncertainties in the assessment of NPP. This assessment should be preferably based on the application of multiple methods, each one characterized by its own pros and cons.

Acknowledgements. This study was supported by the TCOSSiberia project, funded by the European Commission DG Research (EVK2-CT-2001-00131). We would like to gratefully acknowledge to help of A. Shifman in the field activities.

Edited by: T. Laurila

\section{References}

Anthoni, P. M., Law, B. E., Unsworth, M. H., et al.: Carbon and water vapour exchange of an open-canopied ponderosa pine ecosystem, Agric. For. Meteorol., 95, 151-168, 1999.

Aubinet, M., Heinesch, B., and Yernaux, M.: Horizontal and vertical $\mathrm{CO}_{2}$ advection in a sloping forest, Boundary-Layer Meteorol., 108, 397-417, 2003.

Aubinet, M., Grelle, A., Ibrom, A., et al.: Estimates of annual net carbon and water exchange of European forests: the EUROFLUX methodology, Adv. Ecol. Res., 30, 113-175, 2000.

Baldocchi, D.: Assessing the eddy covariance technique for evaluating carbon dioxide exchange rates of ecosystems: past, present and future, Global Change Biol., 9, 479-492, 2003.

Baldocchi, D. D., Finnigan, J. J., Wilson, K. W., et al.: On measuring net ecosystem carbon exchange in complex terrain over tall vegetation, Boundary Layer Meteorol., 96, 257-291, 2000.

Barford, C. C., Wofsy, S. C., Goulden, M. L., et al.: Factors controlling long and short term sequestration of atmospheric $\mathrm{CO}_{2}$ in a mid latitude forest, Science, 294, 1688-1691, 2001.

Batjes, N. H. and Sombroek, W. G.: Possibilities for carbon sequestration in tropical and subtropical soils, Global Change Biol., 3, 161-173, 1997.

Bird, M. I., Chivas, A. R., and Head, J.: A latitudinal gradient in carbon turnover times in forest soils, Nature, 381, 143-146, 1996.

Black, T. A., Den Hartog, G., Neumann, H., et al.: Annual cycles of $\mathrm{CO}_{2}$ and water vapour fluxes and above and within a boreal aspen stand, Global Change Biol., 2, 219-230, 1996.

Ciais, P., Tans, P. P., Trolier, M., White, J. W. C., and Francey, R. J.: A large northern hemisphere terrestrial $\mathrm{CO}_{2}$ sink indicated by the $13 \mathrm{C} / 12 \mathrm{C}$ ratio of atmospheric $\mathrm{CO}_{2}$, Science, 269, 10981101, 1995.

Conen, F., Mikhail, V. Y., and Sambuu, A. D.: Potential for detecting changes in soil organic carbon concentrations resulting from climate change, Global Change Biol., 9, 1515-1520, 2003.

Coupland, R. T.: Mixed Prairie. Grasslands of the World, edited by: Coupland, R. T., Cambridge University Press, 151-182, 1992.
Cuevas, E. and Medina, E.: Nutrient dynamics within Amazonian forests. II. Fine root growth, nutrient availability, and leaf litter decomposition, Oecologia, 76, 222-235, 1988.

Curtis, P. S., Hanson, P. J., Bolstad, P., Barford, C., Randolph, J. C., Schmid, H. P., and Wilson, K. B.: Biometric and eddy covariance based estimates of annual carbon storage in five eastern North American deciduous forests, Agric. For. Meteorol., 113, 3-19, 2002.

Ehman, J. L., Schmid, H. P., Grimmond, C. S. B., et al.: An initial intercomparison of micrometeorological and ecological inventory estimates of carbon exchanges in mid-latitude deciduous forest, Global Change Biol., 8, 575-589, 2002.

Fahey, T. J. and Hughes, J. W..: Fine root dynamics in a northern hardwood forest ecosystem, Hubbard Brook Experimental Forest, NH, J. Ecol., 82, 533-548, 1994.

Falge, E., Baldocchi, D. D., Olson, R., et al.: Gap filling strategies for defensible annual sums of net ecosystem exchange, Agric. For. Meteorol., 107, 43-69, 2001.

Fisk, M. C., Schmidt, S. K., and Seastedt, T. R.: Topographic patterns of above- and belowground production and nitrogen cycling in alpine tundra, Ecology, 79, 2253-2266, 1998.

Flanagan, L. B., Wever, L. A., and Carson, P. J.: Seasonal and interannual variation in carbon dioxide exchange and carbon balance in a northern temperate grassland, Global Change Biol., 8, 599615, 2002.

Gill, R. A., Kelly, R. H., Parton, W. J., Day, K. A., Jackson, R. B., Morgan, J. A., Scurlock, J. M. O., Tieszen, L. L., Castle, J. V., Ojima, D. S., and Zhang, X. S.: Using simple environmental variables to estimate belowground productivity in grasslands, Global Ecol. Biogeogr., 11, 79-86, 2002.

Gilmanov, T. G., Verma, S. B., Sims, P. L., Meyers, T. P., Bradford, J. A., Burba, G. G., and Sukyer, A. E.: Gross primary production and light response parameters of four Southern Plains ecosystems estimated using long term $\mathrm{CO}_{2}$ flux tower measurements, Global Biogeochem. Cycles, 17(2), 1071, 1-16, doi:10.1029/2002GB002023, 2003..

Goulden, M. L., Munger, J. W., Fan, S. M., et al.: Measurements of carbon storage by long term eddy correlation: methods and a critical assessment of accuracy, Global Change Biol., 2, 169$182,1996$.

Grace, J., Malhi, Y., Lloyd, J., et al.: The use of eddy covariance to infer the net carbon dioxide uptake of Brazilian rain forest, Global Change Biol., 2, 209-217, 1996.

Hall, D. O., Ojima, D. S., Parton, W. J., and Scurlock, J. M. O.: Response of temperate and tropical grasslands to $\mathrm{CO}_{2}$ and climate change, J. Biogeography, 22, 537-547, 1995.

Hall, D. O. and Scurlock, J. M. O.: Climate change and productivity of natural grassland, Annals of Botany (Supplement), 67, 49-55, 1991.

IPCC: Good Practice Guidance for LULUCF Sector, Intergovernmental Panel on ClimateChange, Cambridge University Press, Cambridge, UK, 2003.

IPCC: Good Practice Guidance and Uncertainty Management in Greenhouse Gases Inventories, Cambridge University Press, Cambridge, UK, 2000.

Johnson, L. C. and Matchett, J. R.: Fire and grazing regulate belowground processes in tallgrass prairie, Ecology, 12, 3377-3389, 2001.

Jordan, C. F. and Escalante, G.: Root productivity in an Amazonian 
rain forest, Ecology, 6, 14-18, 1980.

Koukura, Z., Mamolos, A. P., and Kalburtji, K. L: Decomposition of dominant plant species litter in a semi arid grassland, Appl. Soil Ecol., 23, 13-23, 2003.

Lauenroth, W. K.: Methods of estimating belowground net primary production, Methods in ecosystem science, edited by: Sala, O. E., Jackson, R. B., Mooney, H. A., and Howarth, R. W., 58-71, Springer, New York, 2000.

Lieth, H. F. H. (Ed.): Patterns of Primary Productivity in the Biosphere, Hutchinsons Ross, Stroudsberrg, PA, 342 pp, 1978.

Lloyd, J. and Taylor, J. A.: On the temperature dependence of soil respiration, Functional Ecology, 8, 315-323, 1994.

Long, S. P., Garcia Moya, E., Imbamba, S. K., et al.: Primary productivity of natural grass ecosystems of the tropics: a reappraisal, Plant Soil, 115, 155-166, 1989.

Long, S. P., Jones, M. B., and Roberts, M. J. (Eds.): Primary Productivity of Grass Ecosystems of the Tropics and Sub-Tropics, Chapman \& Hall, London, 1992.

Mahli, Y., Nobre, A. D., Grace, J., et al.: Carbon dioxide transfer over a central Amazonian rain forest, J. Geophys. Res., 103, 31 593-31 612, 1998.

Meyers, T.: A comparison of summertime water and $\mathrm{CO}_{2}$ fluxes over rangeland for well watered and drought conditions, Agric. For. Meteorol., 106, 205-214, 2001.

Milner, C. and Hughes, R. E.: Methods for the Measurement of the Primary Production of Grassland, IBP Handbook no.6, Blackwell, Oxford, 1968.

Moncrieff, J. B., Mahli, Y., and Leuning, R.: The propagation of errors in long term measurements of land atmosphere fluxes of carbon and water, Global Change Biol., 2, 231-240, 1996.

Neill, C.: Comparison of soil coring and ingrowth methods for measuring belowground production, Ecology, 73, 1918-1921, 1992.

$\mathrm{Ni}$, J.: Estimating net primary productivity of grasslands form field biomass measurements in temperate northern China, Plant Ecology, 174, 217-234, 2004.

Olson, J. S.: Energy storage and the balance of producers and decomposers in ecological systems, Ecology, 44, 322-331, 1963.

Papale, D., Reichstein, M., Canfora, E., Aubinet, M., Bernhofer, C., Longdoz, B., Kutsch, W., Rambal, S.. Valentini, R., Vesala, T., and Yakir, D.: Towards a more harmonized processing of eddy covariance $\mathrm{CO}_{2}$ fluxes: alogorithms and uncertainty estimation, Biogeosciences, 3, 571-583, 2006,

http://www.biogeosciences.net/3/571/2006/.

Papale, D. and Valentini, R.: A new assessment of European forests carbon exchanges by eddy fluxes and artificial neural network spatialization, Global Change Biol., 9, 525-535, 2003.

Paruelo, J. M., Epstein, H. E., Lauenroth, W. K., and Burke, I. C.: ANPP estimates from NDVI fort he central Grassland Region of the United States, Ecology, 78, 953-958, 1977.

Persson, H.: The distribution and productivity of fine roots in boreal forests, Plant Soil, 71, 87-101, 1983.

Raich, J. W., Russel, A. E., and Vitousek, P. M.: Primary productivity and ecosysytem development along an elevational gradient on Mauna Loa, Hawaii, Ecology, 78, 707-721, 1997.

Reichstein, M., Falge, E., Baldocchi, D., Papale, D., Aubinet, M., Berbigier, P., Bernhofer, Buchmann, N., Gilmanov, T., Granier, A., Grünwald, T., Havránková, K., Ilvesniemi, H., Janous, D., Knohl, A., Laurila, T., Lohila, A., Loustau, D., Matteucci, G., Meyers, T., Miglietta, F., Ourcival, J., Pumpanen, J., Rambal, S.,
Rotenberg, E., Sanz, M., Tenhunen, T., Seufert, G., Vaccari, F., Vesala, T., Yakir, D., and Valentini, R.: On the separation of net ecosystem exchange into assimilation and ecosystem respiration: review and improved algorithm, Global Change Biol., 11, 14241439, 2005.

Sala, O. E. and Austin, A. T.: Methods for estimating aboveground net primary productivity, Methods in ecosystem science, edited by: Sala, O. E., Jackson, R. B., Mooney, H. A., and Howarth, R. W., 31-43, Springer, New York, 2000.

Schulze, E. D., Wirth, C., and Heimann, M.: Managing forests after Kyoto, Science, 289, 2058-2059, 2000.

Scurlock, J. M. O., Johnson, K., and Olson, R. J.: Estimating net primary productivity from grassland biomass dynamics measurements, Global Change Biol., 8, 736-753, 2002.

Sims, P. L. and Risser, P. G.: Grasslands, in: Northern American Terrestrial Vegetation, edited by: Barbour, M. G. and Billings, W. D., 2nd ed. Cambridge University Press, Cambridge, 323 356, 2000.

Singh, J. S. and Joshi, M. C.: Tropical grasslands primary production, in: Grassland Ecosystems of the World, edited by: Coupland, R. T., Cambridge University Press, 197-218, 1975.

Schuepp, P. H., Leclerc, M. Y., MacPherson, J. I., and Desjardins, R. L.: Footprint predictions of scalar fluxes using analytical solutions of the diffusion equation, Boundary-Layer Meteorol., 50, 355-373, 1990.

Smith, P.: How long before a change in soil organic carbon can be detected?, Global Change Biol., 10, 1878-1883, 2004.

Stolbovoi, V.: Soils of Russia: Correlated with the Revised Legend of the FAO Soil Map of the World and World Reference Base for Soil Resources, Research Report, RR-00-13, IIASA, Laxenburg, Austria, 2000.

Suyker, A. E. and Verma, S. B.: Year round observations of the net ecosystem exchange of carbon dioxide in a native tallgrass prairie, Global Change Biol., 7, 179-189, 2001.

Titlianova, A. A.: Biological Cycle of carbon in grassland ecosystems, Novosibirsk (in Russian), 1977.

Titlianova, A. A., Mironcheva-Tokareva, N. P., Romanova, I. P., Kosykh, N. P., Kyrgys, Ch. O., and Sambuu, A. D.: Productivity of steppes, in: Steppes of Central Asia, edited by: Gadghiev, I. M., Korolyuk, A. Yu., Titlianova, A. A., Khmelev, V. A., et al., Novosibirsk, SB RAS (in Russian), 95-112, 2002.

Thornthwaite, C. W.: The Climates of the Earth, Geographical Rev., 23(3), 433-440, 1933.

Trumbore, S. E., Chadwick, O. A., and Amundson, R.: Rapid exchange between soil carbon and atmospheric carbon dioxide driven by temperature change, Science, 272, 393-396, 1996.

Valentini, R., Matteucci, G., Dolman, A. J., and Schulze, E. D.: The role of canopy flux measurements in global C-cycle research, in: Fluxes of Carbon, Water and Energy of European Forests, edited by: Valentini, R., Springer Verlag, 255-266, 2003.

Webb, E. K., Pearman, G., and Leuning, R.: Correction of flux measurements for density effects due to heat and water vapour transfer, Q. J. Roy. Meteor. Soc., 106, 85-100, 1980.

Weigert, R. G. and Evans, F. C.: Primary production and the disappearance of dead vegetation on an old field in south-eastern Michigan. Ecology, 45, 49-63, 1964. 